\title{
Kajian Sistem Drainase Kota Labuan Bajo di Nusa Tenggara Timur
}

\author{
Tatas $^{1)}$, Denik Sri Krisnayanti ${ }^{2)}$, Mahendra Andiek Maulana ${ }^{3)}$ \\ 1) Program Studi Diploma Teknik Sipil FTSP ITS, Surabaya \\ ${ }^{2)}$ Jurusan Teknik Sipil FT Universitas Cendana, Kupang \\ ${ }^{3)}$ Jurusan Teknik Sipil FTSP ITS, Surabaya \\ Email: tatas@ce.its.ac.id ${ }^{1)}$,denik219@yahoo.com ${ }^{2}$, mahendrasipil@gmail.com ${ }^{3)}$
}

\begin{abstract}
Labuan Bajo is located in Komodo district, West Manggarai regency, East Nusa Tenggara Province. Mainland territory covers western part of Flores Island and several small islands around it, such as Komodo and Rinca Island which is the habitat of rare animals, Komodo. As transit towards habitat komodos, Labuan Bajo city is experiencing rapid development. The development must also be balanced by an adequate drainage system. In this paper will be delivered inundation problems occur, runoff water flow patterns, and the proposed drainage treatment zone.

The methodology is used to conduct surveys directly to the site, to see the topography, the main river. In addition, by using a computer program that is able to read and perform topographic delineation of watershed boundaries automatically using Gridded Surface Subsuface Hydrology Analysis (GSSHA). Based on the analysis it can be concluded that the inundation topography is hilly and is not supported by adequate drainage, runoff flow patterns that go directly to the sea and there are first accommodated by major rivers, drainage treatment system can be divided four zones based on the catchment of Waebo, Waemata, Waekemiri, and Waemese.
\end{abstract}

Keywords: cathment area, Labuan Bajo, system drainage.

Abstrak

Kota Labuan Bajo terletak di Kecamatan Komodo, Kabupaten Manggarai Barat, Provinsi Nusa Tenggara Timur. Kabupaten Manggarai Barat merupakan hasil pemekaran dari Kabupaten Manggarai berdasarkan Undang Undang No. 8 Tahun 2003. Wilayahnya meliputi daratan Pulau Flores bagian Barat dan beberapa pulau kecil di sekitarnya, diantaranya adalah Pulau Komodo dan Pulau Rinca yang merupakan habitat binatang langka, komodo. Sebagai transit menuju habitat komodo, maka Kota Labuan Bajo mengalami pembangunan yang pesat. Pembangunan tersebut harus diimbangi pula oleh sistem drainase yang memadai. Dalam makalah ini akan disampaikan permasalahan genangan yang terjadi, pola aliran air limpasan, dan usulan zona penanganan drainase.

Adapun metodologi yang digunakan adalah dengan melakukan survei secara langsung ke lokasi, dengan melihat topografi, sungai utama. Selain itu dengan menggunakan beberapa program komputer yang mampu membaca topografi dan melakukan deliniasi batas daerah aliran sungai secara otomatis menggunakan Gridded Surface Subsuface Hydrology Analysis (GSSHA).

Berdasarkan analisis maka dapat diambil kesimpulan bahwa genangan akibat topografi yang berbukit-bukit dan tidak didukung oleh saluran drainase yang memadai, pola aliran limpasan air yaitu langsung menuju ke laut dan ada yang ditampung terlebih dahulu oleh sungai-sungai utama, sistem penanganan drainase dapat dibagi empat zona berdasarkan daerah tangkapan hujan yaitu DAS Waebo, DAS Waemata, DAS Waekemiri, DAS Waemese.

Kata Kunci: daerah aliran sungai, Labuan Bajo, sistem drainase.

1. Pendahuluan

Kota Labuan Bajo terletak di

Kecamatan Komodo, Kabupaten
Manggarai Barat, Provinsi Nusa Tenggara Timur. Kabupaten Manggarai Barat merupakan hasil pemekaran dari

Jurnal APLIKASI: Media Informasi \& Komunikasi Aplikasi Teknik Sipil Terkini Halaman 25 
Kabupaten Manggarai berdasarkan Undang Undang No. 8 Tahun 2003. Wilayahnya meliputi daratan Pulau Flores bagian Barat dan beberapa pulau kecil di sekitarnya, diantaranya adalah Pulau Komodo dan Pulau Rinca yang merupakan habitat binatang langka, komodo. Kota Labuan Bajo sendiri merupakan gabungan dari 2 kelurahan dan 4 desa yang merupakan bagian dari Kecamatan Komodo. Desa dan kelurahan yang menjadi bagian Kota Labuan Bajo adalah Kelurahan Labuan Bajo, Kelurahan Waekelambu, Desa Batu Cermin, Desa Gorontalo, Desa Gorobilas, dan Desa Nggorang. Kota Labuan Bajo ini (lihat Gambar 1), merupakan ibu kota dari Kabupaten Manggarai Barat. Kota ini secara administratif dibatasi oleh Laut Flores (Utara-Barat), Desa Tanjungboleng, Desa Potangwangka, Desa Cuncawulang (Timur), Desa Cuncawulang, Desa Watunggelek, Desa Macangtanggar (Selatan).

Sebagai wilayah yang sedang berkembang, dengan potensi wisata yang menjanjikan maka perlu dilakukan penataan kawasan terutama yang menyangkut sistem drainase perkotaan. Sistem drainase perkotaan yang akan dikaji meliputi peta kawasan genangan, drainase mikro dan drainase makro.

\section{Metodologi}

Metodologi yang digunakan adalah dengan cara melakukan survey secara langsung ke lapangan dengan menggunakan peralatan survey seperti GPS (Global Potitioning System), Peta
Kota Labuan Bajo, dan alat ukur pemetaan (teodolit). Survei lapangan tersebut untuk memetakan kawasan genangan, dimensi saluran, dan arah aliran.

Pengolahan data topografi dengan menggunakan penggambaran dengan memanfaatkan Cad-System, program bantu deliniasi batas daerah aliran sungai dengan menggunakan metode Grided Surface Subsurface Hydrology Analysis (Downer dan Odgen 2002), serta program bantu pengolahan topografi, Global Mapper. Pengolahan data topografi tersebut akan mendapatkan pola aliran, batas daerah tangkapan hujan, luas daerah aliran sungai, kemiringan rata-rata, panjang sungai dan lain-lain.

Penentuan peta tata guna lahan dengan memanfaatkan peta yang dapat diperoleh melalui Google Map, kemudian melakukan teknik overlay untuk mengelompokkan tutupan lahan yang utama di Kota Labuhan Bajo.

\section{Hasil dan Pembahasan}

Berdasarkan survei lapangan dan pengukuran lapangan maka dapat diidentifikasi bahwa di Kota Labuan Bajo permasalahan yang muncul adalah berupa genangan-genangan setempat yang diakibatkan oleh hujan lokal dan kondisi lahan yang bergelombang, sehingga mempersulit aliran air menuju saluran drainase terdekat. Gambar 2 menunjukkan wilayah genangan di Kota Labuan Bajo meliputi (1) Jalan Pantai Pede (sekitar muara Sungai Waekemiri), Desa Gorontalo dengan 
luas genangan 0,04 ha, tinggi genangan 0,35 meter dan lama genangan 45 menit; (2) beberapa ruas di Jalan Soekarno-Hatta dengan luasan total mencapai 0,084 ha, dengan ketinggian 0,35 meter dan lama genangan mencapai 45 menit; (3) Kawasan Cowang Dereng dengan luasan genangan sekitar 1 ha, setinggi 0,5-1 meter dengan durasi waktu hingga 2 jam; (4) Kawasan pendidikan di Jalan Mangga Golek, dengan luas genangan mencapai 0,06 ha, tinggi genangan 0,40 meter dan lama genangan mencapai 1 jam; selain itu ada beberapa titik genangan dengan penyebab rata-rata adalah topografi wilayah yang berupa cekungan sehingga menyebabkan kesulitan dalam pematusan air seperti di Kawasan Permukiman King Road Waimata dan Jembatan Waimata, Pasar Baru di Desa Gorontalo, dan sekitar Kantor Bupati.

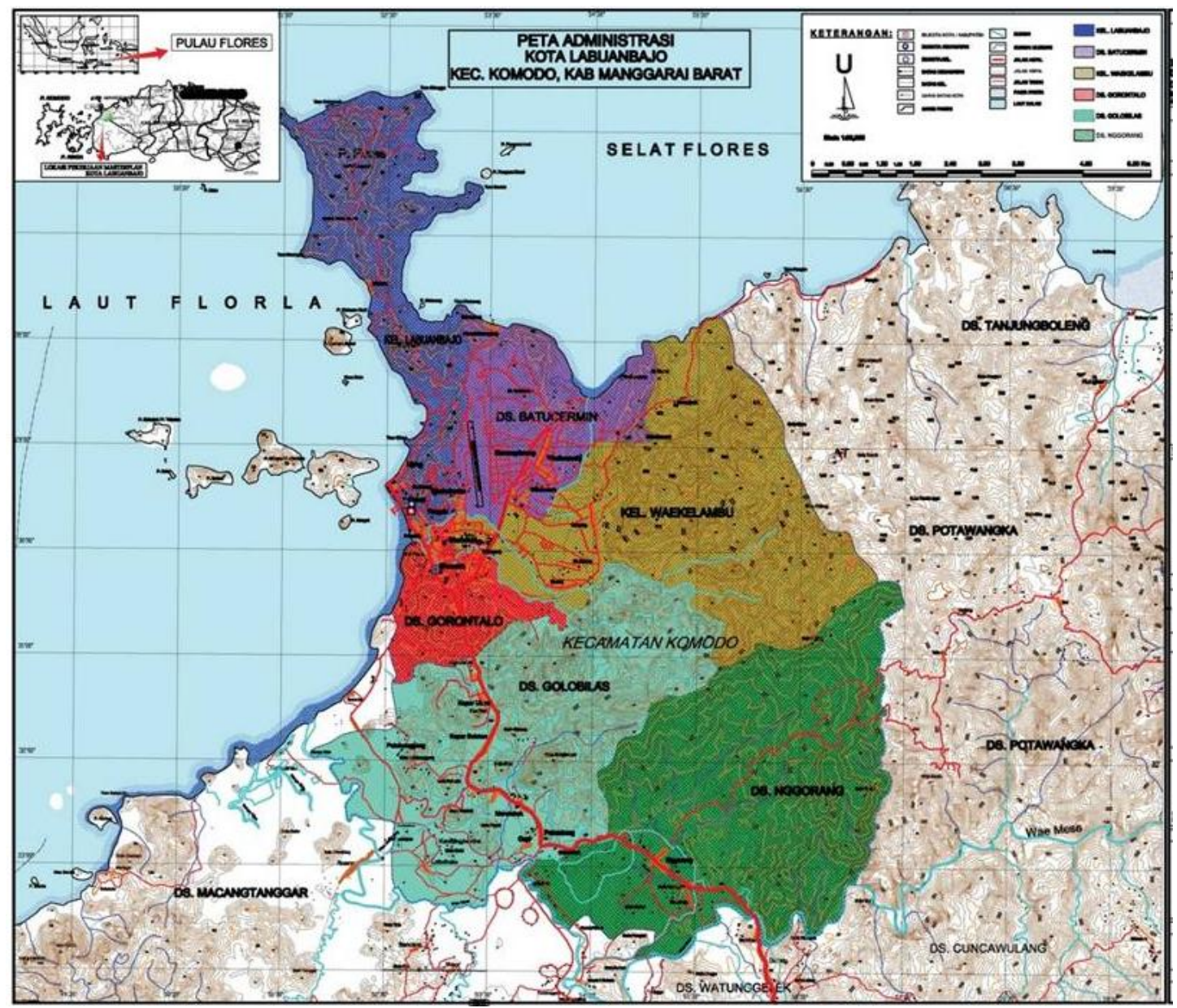

Gambar 1. Kota Labuan Bajo (Tatas, dkk 2012)

Selanjutnya deliniasi batas daerah aliran sungai dengan menggunakan peta topografi dapat dilihat pada Gambar 3.
Arah aliran limpasan permukaan di Kota Labuan Bajo memiliki dua karakteristik yang berbeda yaitu arah aliran yang langsung menuju ke laut 
dan arah aliran air yang terlebih dahulu ditampung dalam cathment area.

Berdasarkan proses deliniasi batas daerah aliran sungai, maka Kota Labuan Bajo dapat terbagi menjadi empat DAS yaitu DAS Waebo, DAS Waemata, DAS Waekemiri dan DAS Waemese (Gambar 4).

Batas DAS Waebo, yang berada di bagian utara Kota Labuan Bajo, adalah sebagai berikut: batas sebelah Utara adalah Selat Flores, sebelah Barat Desa Cowangdereng, sebelah Selatan Desa Senaru, dan sebelah Timur Kelurahan Waekelambu. Sedangkan wilayah yang dilintasi oleh Sungai Waebo yaitu Lancang, Waemaso, Cowangdereng, dan Waekesambi.

Bagian Hulu Sungai Waebo berada di Bukit Senaru dengan hilir di Laut Flores. Panjang sungai ini sekitar 3,03 $\mathrm{km}$. Luas DAS Waebo adalah 5,44 $\mathrm{km}^{2}$ dengan kemiringan lahan tangkapan hujan sekitar $17 \%$.

DAS Waemata berada di tengah Kota Labuan Bajo dengan hulu di Golo Gulung dan bermuara di Laut Flores. Batas DAS ini di bagian Utara adalah Kelurahan Waekelambu, sebelah Barat adalah Laut Flores, di bagian Selatan terdapat Desa Gorontalo dan Desa Golobilas, sedangkan di bagian Timur terdapat Desa Potawangka.

Panjang Sungai Waemata mencapai $8,47 \mathrm{~km}$ sedangkan luas DAS Waemata adalah 17,86 $\mathrm{km}^{2}$. Kemiringan lahan DAS Waemata ratarata $10 \%$. Bagian hulu DAS ini memiliki topografi yang lebih curam jika dibandingkan dengan bagian hilir.

Daerah Aliran Sungai Waekemiri juga mengalir di pusat Kota Labuan Bajo dengan hulu di Golo Bilas dan bermuara di Laut Flores. Batas Utara adalah DAS Waekemiri, sebelah Barat terdapat Laut Flores, sedangkan sebelah Selatan adalah DAS Waemese dan sebelah Timur terdapat DAS Waekemiri. Panjang Sungai Waekemiri adalah 5,16 km dengan luas daerah aliran sungai $8,616 \mathrm{~km}^{2}$. Kemiringan lahan rata-rata DAS Sungai Waekemiri adalah $4 \%$ dengan variasi topografi sama dengan DAS Waemata yaitu di bagian hulunya banyak yang curam sedangkan di bagian hilir lebih landai.

Daerah Aliran Sungai Waemese merupakan daerah tangkapan hujan yang terbesar di Kota Labuan Bajo. Sebagian dari DAS ini masuk di dalam Kota Labuan Bajo. Topografi DAS Waemese adalah pegunungan dan hutan dan membentuk banyak sungaisungai kecil. Luas DAS secara keseluruhan lebih dari $51,25 \mathrm{~km}^{2}$.

\section{Simpulan}

Berdasarkan uraian tersebut maka beberapa kesimpulan terkait sistem drainase di Kota Labuan bajo adalah sebagai berikut:

1. Genangan yang timbul dibeberapa titik di Kota Labuan Bajo memiliki sifat lokal, akibat hujan lokal yang terjadi dan akibat topografi yang berbukit-bukit dan selain itu juga 
karena tidak didukung oleh saluran drainase yang memadai.

2. Pola aliran limpasan air terbagi menjadi dua sistem yaitu yang langsung menuju ke laut dan ada yang ditampung terlebih dahulu oleh sungai-sungai utama.

3. Secara penanganan sistem drinase, Kota Labuan Bajo dapat dibagi dalam empat sistem penanganan (zona), sistem penanganan tersebut didasarkan kepada daerah tangkapan hujan yaitu DAS Waebo, DAS Waemata, DAS Waekemiri, DAS Waemese.

Ucapan Terimakasih

Terima kasih kepada Ir. Poedji Watono, yang telah memberikan kepercayaan dalam hal melakukan kajian sistem drainase di wilayah studi.

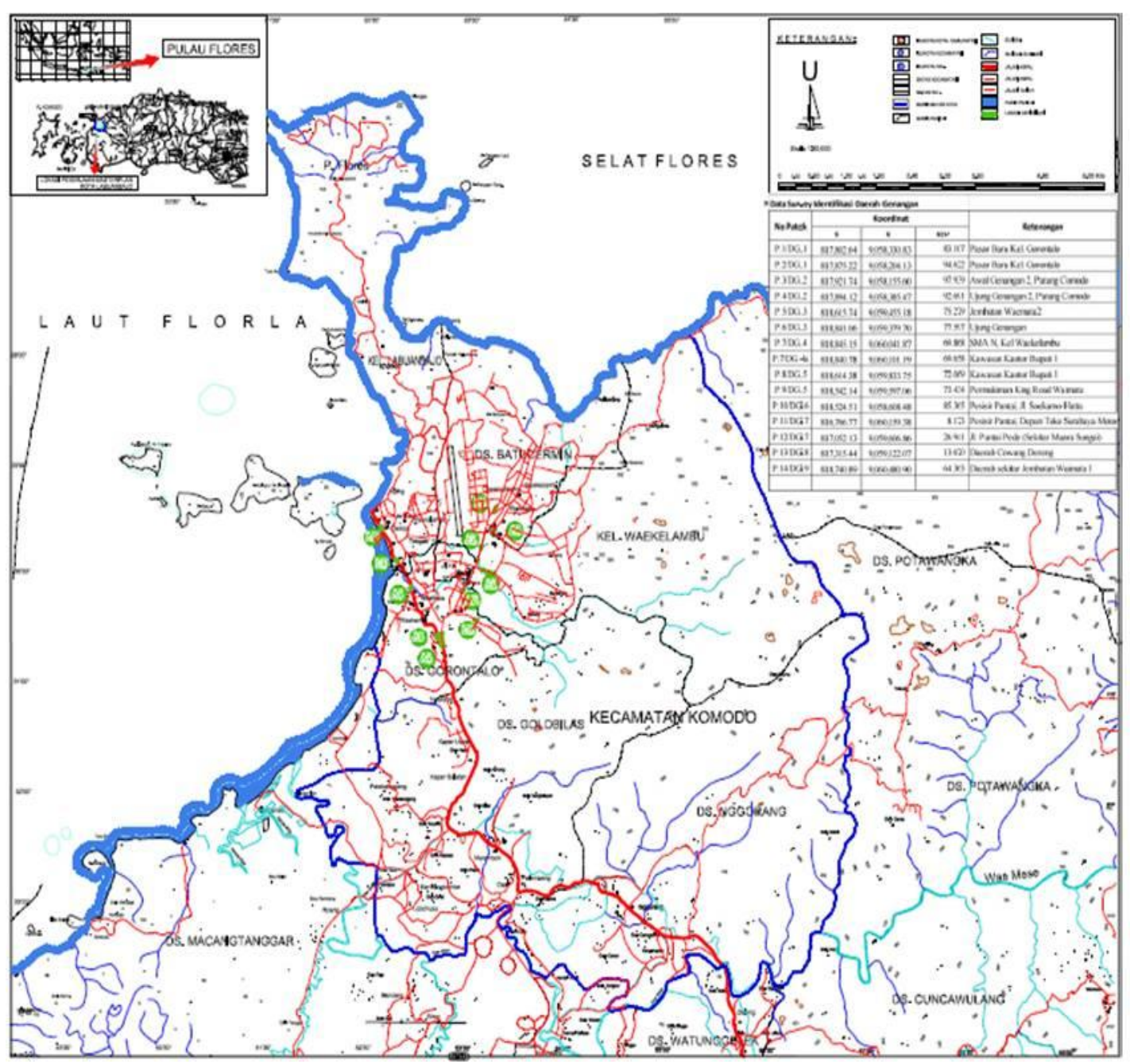

Gambar 2. Titik genangan di Kota Labuan Bajo (Tatas, dkk 2012) 


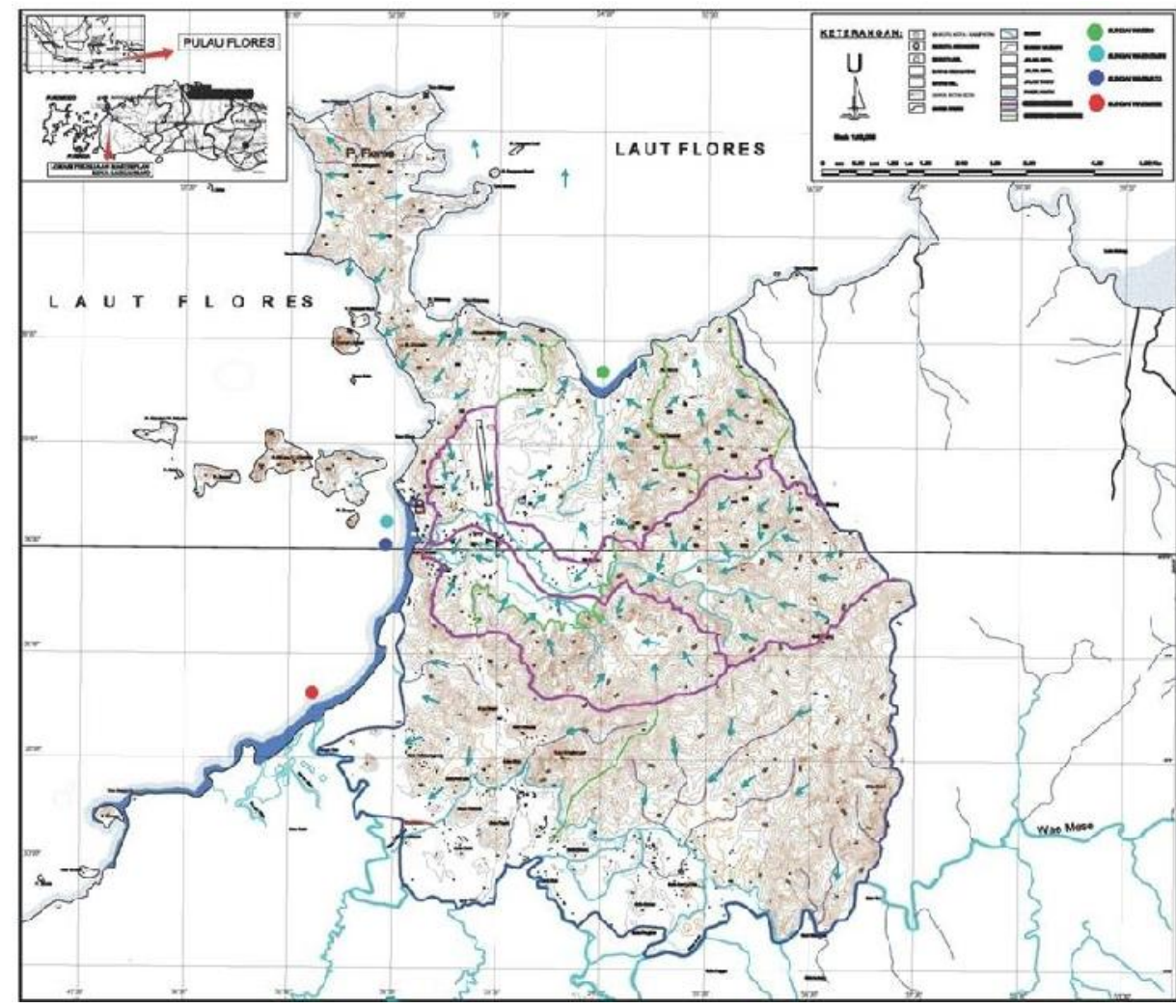

Gambar 3. Pola aliran di Kota Labuan Bajo (Tatas, dkk 2012)

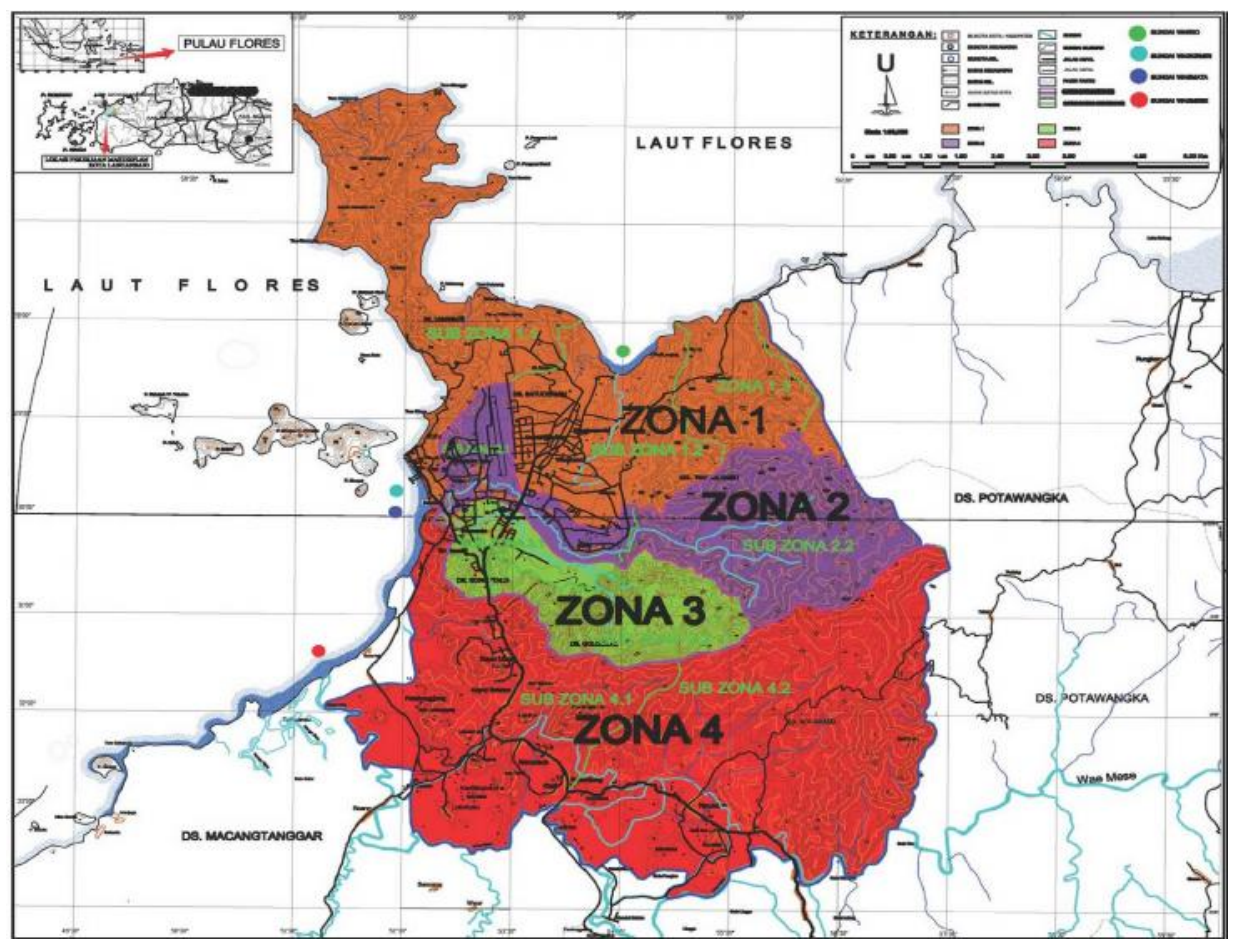

Gambar 4. Pembagian DAS di Kota Labuan Bajo dalam empat sistem penanganan (Zona 14) secara berurutan adalah DAS Waebo, DAS Waemata, DAS Waekemiri dan DAS Waemese (Tatas, dkk 2012) 
Jurnal APLIKASI

ISSN.1907-753X

Daftar Pustaka

Downer, C. W. dan Odgen, F. L. 2002. GSSHA-User's Manual: Gridded Surface Subsurface Hydrologic Analysis, Engineering Research Development Center, Vicksburg.

Tatas, Krisnayanti dan Maulana, 2012. Laporan Akhir "Review Master Plan dan DED Kota Labuan Bajo Kabupaten Manggarai Barat”. Propinsi NTT: PT. Global

Parasindo Jaya, Dinas Cipta

Karya. 
Halaman ini sengaja dikosongkan 